\title{
Transport patterns in community-dwelling adults aged 50 years and over in Ireland
}

Orna Donoghue, Joanna Orr, Siobhan Leahy, Rose Anne Kenny

On behalf of the TILDA team

April 2017 
Copyright (C) The Irish Longitudinal Study on Ageing 2017

The Irish Longitudinal Study on Ageing

Lincoln Place

Trinity College Dublin

Dublin 2

Tel: +35318964120

Email: tilda@tcd.ie

Website: www.tilda.ie

https://www.doi.org/10.38018/TildaRe.2017-02 



\section{Key Findings}

- Nine out of ten adults aged 50 years and over in Ireland (89\%) travel mainly by car (as a driver or passenger) while one in ten (9\%) rely on public transport.

- As people get older, they are less likely to drive themselves and more likely to rely on lifts from others. This is particularly evident in women where $72 \%$ of $50-64$ year olds drive themselves compared to $30 \%$ of those aged $\geq 75$ years; in contrast, $17 \%$ of $50-64$ years olds travel mainly as car passengers compared to $55 \%$ of those aged $\geq 75$ years.

- Use of public transport increases only marginally with age, which may reflect both the greater convenience of travelling by car and the lack of suitable public transport options available.

- One-quarter of adults living in Dublin city/county rely mainly on public transport compared to just $2 \%$ of adults in rural areas, reflecting the vast difference in transport services available. $58 \%$ of adults living in rural areas rate the public transport services in their area as poor or very poor. Common issues include limited bus routes or threatened closure of existing routes, inconvenient schedules and low frequency of services.

- One in five adults aged 75 years and over and living in rural areas (19\%) indicate that the lack of local transport facilities affects their lifestyle. $12-18 \%$ of the same age group indicate that reduced frequency of driving or no longer driving affects their ability to socialise, attend business-related appointments and health/social care appointments.

- Adults whose main mode of transport is driving themselves or travelling by public transport report greater participation in social activities and volunteering compared to those who rely on lifts from others.

- Non-drivers (including those who used to drive in the past) report higher levels of depressive symptoms and loneliness and lower quality of life compared to current drivers. However, non-driving men are more likely to report intimate social relationships compared to current drivers suggesting that their reliance on others for lifts may provide an opportunity for enhanced social interactions with others.

- As the population ages, there is an increasing need for improved transport networks and services that meet the specific needs of older adults, especially in rural areas. 


\section{Acknowledgements}

We acknowledge the vision and commitment of our study funders, The Atlantic

Philanthropies, the Department of Health and Irish Life plc. We would like to state that any views expressed in this report are not necessarily those of the Department of Health or of the Minister of Health. We acknowledge the Road Safety Authority who provided support for this research project. Finally, we would like to thank the TILDA participants without whom this research would not be possible. 


\section{Contents}

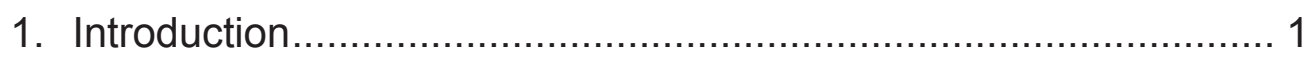

2. Characteristics of adults aged 50 years and over in Ireland .......... 3

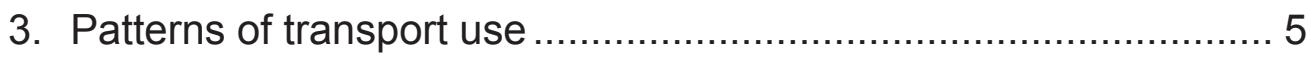

4. Importance of driving and current driving status ........................11

5. Evaluation of public and private transport options..................... 18

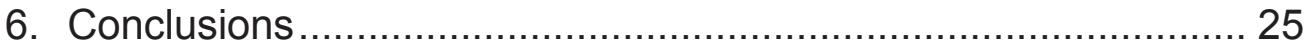

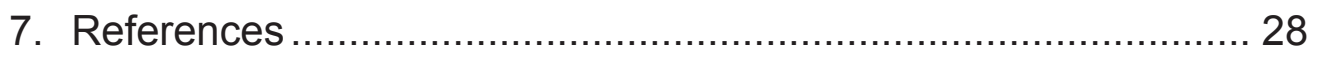




\section{Introduction}

Travel is often required to facilitate appropriate access to essential services (e.g. shops, banks, post offices, GP clinics, etc), and increased opportunities for work, volunteering, and social and cultural activities. It allows a more active lifestyle and promotes increased social engagement and interactions with others, fostering a sense of independence and improved quality of life (Gilhooley et al, 2003; Davey et al, 2007; Green et al, 2007). A reduction in mobility, driving or available public transport options can affect the ability to attend these activities regularly and spontaneously and this often represents a huge lifestyle shift and a sense of loss of independence.

A two-fold increase in the Irish population aged 65 years and over has been projected for 2041 (Central Statistics Office, 2007) which will lead to an increase in the number of older drivers. However, as people get older, their patterns of transport use will change leading to increasing numbers relying on public transport or family and friends for transport. In Ireland, there is a need to address these challenges of population ageing to ensure that the transport options available cater for the specific requirements of older users. This need has also been highlighted in several other countries including the UK and US (HolleyMoore and Creighton, 2011; Lynott and Figueiredo, 2009).

In this report, we examine the patterns of transport use in community-dwelling adults aged 50 years and older in Ireland. While a previous TILDA report highlighted that a large proportion of older adults in Ireland are regular walkers (Donoghue et al, 2016), this report focuses on the use of cars, buses, trains and bicycles for transport. We examine how patterns of use change with increasing age and the associations between travelling by car or public transport and social participation, mental health and wellbeing.

\subsection{Data and Methods}

This report uses data collected during the first wave of The Irish Longitudinal Study on Ageing (TILDA), a prospective study of 8,172 community-dwelling adults aged 50 years and older in Ireland. Social interviewers visited the respondents in their own homes to complete a comprehensive Computer Assisted Personal Interview (CAPI). This included 
detailed questions on socio-demographics, living circumstances, income and wealth, physical, mental and behavioural health, health care utilization, social participation and transport. Participants were also asked to fill out a self-completion questionnaire (SCQ) which included more sensitive questions about relationships and experiences of growing older. Finally, participants were invited to take part in a comprehensive health assessment either in a dedicated health centre or in their own homes. This report uses data from the CAPI and SCQ only. Data collection took place between October 2009 and February 2011.

\subsection{Statistical Methods and Weighting}

In this report, the percentage of respondents classified into different groups or average scores (means) on the different outcome scales are presented. Most estimates are provided with a $95 \%$ confidence interval. This can be interpreted as a $95 \%$ chance that the sampled confidence interval includes the true population value. All estimates are weighted to account for age, sex and educational attainment in the 2011 Census, ensuring that these estimates are representative of the whole population aged 50 years and over in Ireland.

\subsection{Structure of the Report}

The report is organised as follows. Section 1 provides a background to the topic describing the importance of transport, especially in the context of an ageing population. Section 2 describes the characteristics of adults aged 50 years and over resident in Ireland. Section 3 describes the patterns of transport use (other than walking) and how these vary with age, sex and local area. Section 4 explores the importance of driving and the impact of reducing or stopping driving while Section 5 explores the role of public transport and older adults' views on this. Finally, Section 6 summarises the findings, highlights the relevance to successful ageing and suggests areas in which these findings could inform transport policy. 


\section{Characteristics of adults aged 50 years and over in Ireland}

Descriptive characteristics of 8,172 TILDA participants are shown in Table 1.

Basic demographic indicators (age, sex, educational status) were obtained. Educational status was defined as primary, secondary or tertiary corresponding to $\leq 8,9-13$ and $>13$ years of education respectively. Marital status (married, single, separated/divorced, widowed) and local area (Dublin city or county, another town/city, rural area) were also obtained. Participants reported if a doctor had ever diagnosed them with any of the following conditions: heart attack, heart failure, angina, stroke, transient ischemic attack, heart murmur, diabetes, high blood pressure, high cholesterol, Parkinson's disease, cataracts, glaucoma, age-related macular degeneration, chronic lung disease, asthma, arthritis, osteoporosis, cancer and hip fracture. The number of health conditions reported were categorised as 0, 1, 2 and 3 or more conditions. Participants also self-rated their health relative to others of similar age as Excellent, Very good, Good, Fair or Poor.

Over half (57\%) were aged between 50 and 64 years, while one in five $(21 \%)$ were 75 years or over (Table 1). $51 \%$ of the population aged 50 and over were women and the majority were married (66\%). Almost one in four (23\%) lived in Dublin city or county while half lived in rural areas (49\%). Half reported none or only one health condition while $22 \%$ and $28 \%$ reported 2 conditions and 3 or more conditions respectively.

There were some gender differences, most notably that women were more likely to be widowed (23\% versus $9 \%$ ) and to have at least 3 health conditions ( $31 \%$ versus $24 \%$ ) compared to men. There were also age-related differences, for example, in comparison to those aged 50-64 years, the oldest group aged 75 years and older were less likely to have secondary or tertiary education (48\% versus $78 \%$ ) and more likely to be widowed (44\% versus $5 \%$ ). The oldest group were also in poorer health; more likely to have three or more health conditions ( $49 \%$ versus $17 \%$ ) and to rate their health as fair or poor (32\% versus $20 \%)$. 
Table 1. Descriptive characteristics of adults aged 50 years and over in Ireland

\begin{tabular}{|c|c|c|c|}
\hline & Men & Women & Total \\
\hline & $\mathbf{N}(\%)$ & $\mathbf{N}(\%)$ & $\mathbf{N}(\%)$ \\
\hline \multicolumn{4}{|l|}{ Age } \\
\hline $50-64$ years & $2,078(57.5)$ & $2,588(55.8)$ & 4,666 (56.6) \\
\hline $65-74$ years & $1,068(22.1)$ & $1,096(22.1)$ & $2,164(22.1)$ \\
\hline$\geq 75$ years & $597(20.4)$ & $745(22.2)$ & $1,342(21.3)$ \\
\hline \multicolumn{4}{|l|}{ Education } \\
\hline Primary level & $1,248(34.8)$ & $1,256(30.5)$ & $2,504(32.6)$ \\
\hline Secondary level & $1,454(46.7)$ & $1,809(51.2)$ & $3,263(49.0)$ \\
\hline Tertiary level & $1,040(18.5)$ & $1,361(18.3)$ & $2,401(18.4)$ \\
\hline \multicolumn{4}{|l|}{ Marital status } \\
\hline Married & $2,684(70.8)$ & $2,764(60.6)$ & $5,448(65.7)$ \\
\hline Single & $547(15.1)$ & $432(9.0)$ & $979(12.0)$ \\
\hline Widowed & $303(8.6)$ & $891(23.3)$ & $1,194(16.0)$ \\
\hline Divorced/Separated & $209(5.5)$ & $342(7.1)$ & $551(6.3)$ \\
\hline \multicolumn{4}{|l|}{ Local area } \\
\hline Dublin (city or county) & $859(21.6)$ & $1,077(23.7)$ & $1,936(22.7)$ \\
\hline Other town/city & $1,060(28.4)$ & $1,250(28.5)$ & $2,310(28.5)$ \\
\hline Rural area & $1,817(50.0)$ & $2,097(47.8)$ & $3,914(48.9)$ \\
\hline \multicolumn{4}{|l|}{ Health conditions } \\
\hline 0 conditions & $968(26.4)$ & $875(19.3)$ & $1,843(22.8)$ \\
\hline 1 condition & 1,051 (27.9) & $1,192(26.3)$ & $2,243(27.1)$ \\
\hline 2 conditions & $814(21.5)$ & $1,019(22.9)$ & $1,833(22.2)$ \\
\hline$\geq 3$ conditions & $900(24.2)$ & $1,335(31.5)$ & $2,235(27.9)$ \\
\hline \multicolumn{4}{|l|}{ Self-rated health } \\
\hline Excellent & $545(13.5)$ & 729 (15.3) & $1,274(14.4)$ \\
\hline Very good & $1,087(28.8)$ & $1,246(27.6)$ & $2,333(28.2)$ \\
\hline Good & 1,228 (33.6) & $1,436(32.9)$ & 2,664 (33.3) \\
\hline Fair & $694(19.1)$ & 789 (18.6) & $1,483(18.8)$ \\
\hline Poor & $188(5.1)$ & $229(5.6)$ & $417(5.3)$ \\
\hline
\end{tabular}




\section{Patterns of transport use}

\subsection{Patterns of transport use by demographic factors}

During the interview, participants were asked to choose from a list, all modes of transport that they used regularly (i.e. more than twice in the last twelve months). Three-quarters (74\%) of adults aged 50 years and over reported driving regularly while $39 \%$ reported travelling as a passenger in a car. One quarter (24\%) used the bus regularly while $17 \%$ used trains or trams and $14 \%$ used taxis/hackneys. Only $6 \%$ travelled by bicycle or motorbike regularly while $1 \%$ did not use any of these modes of transport. There were clear differences between men and women (Figure 1) with women less likely to drive themselves or cycle but more likely to travel as a passenger in a car or by bus compared to men.

Figure 1. Modes of transport used regularly (i.e. at least twice in the last year), by sex

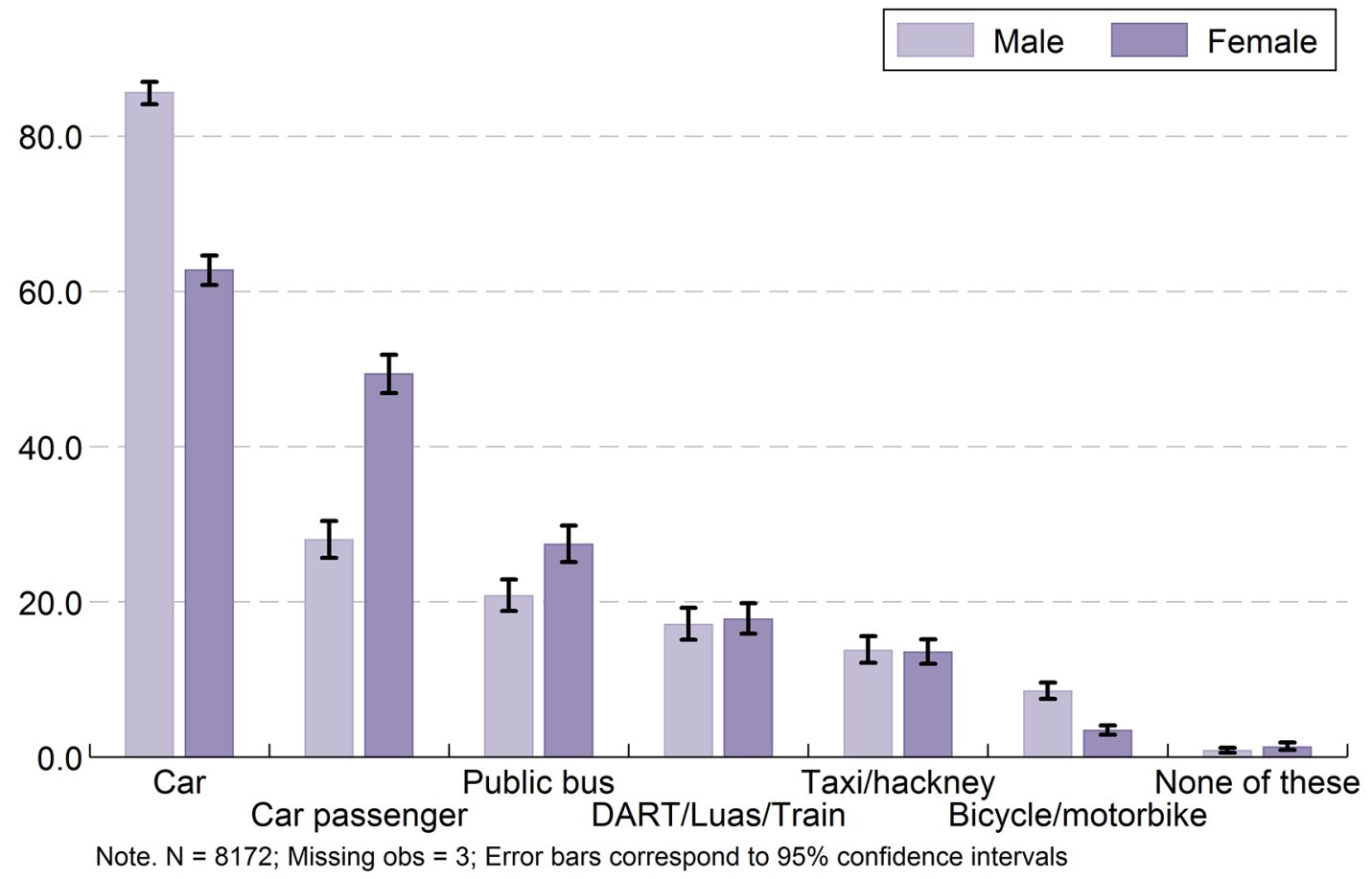


Driving became less common with increasing age, especially in those aged 75 years and over and this corresponded to an increase in being driven by others (Figure 2), however driving was still the most popular form of transport in all age groups. Use of public transport was relatively similar across all age groups (bus: 22-28\%; train: 11-17\%) while travel by bicycle/motorbike reduced with increasing age (8\% in 50-64 year olds to $2 \%$ in those aged 75 years and over).

Figure 2. Modes of transport used regularly (i.e. at least twice in the last year), by age group

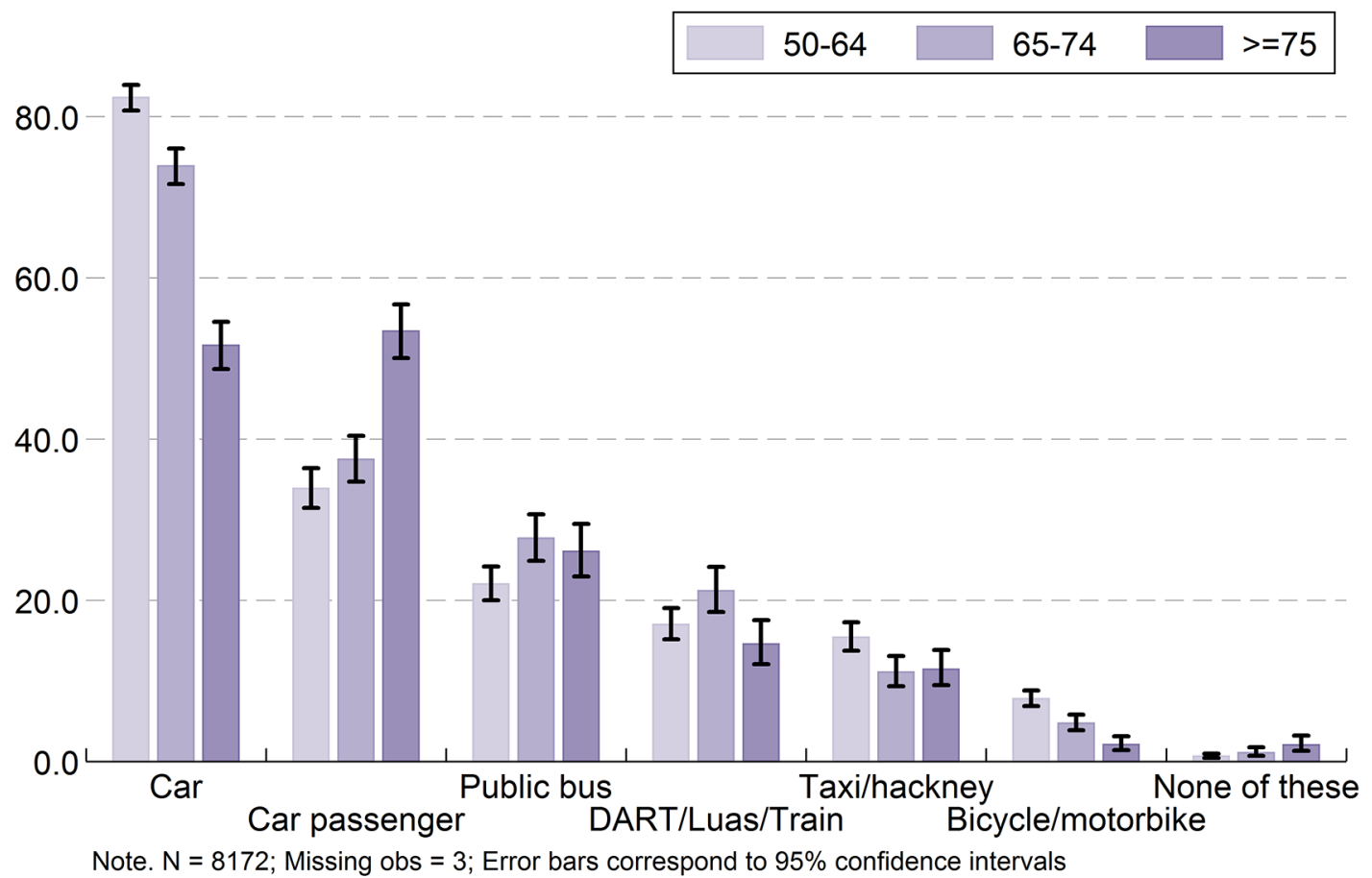

When asked about the mode of transport used most often, three main forms of transport emerged - driving (71\%), travelling as a passenger in a car (18\%) and public transport including bus and rail services $(9 \%)$ while $3 \%$ reported other modes of transport. Figure 3 illustrates that the reduction in driving with increasing age is more pronounced in women ( $72 \%$ in $50-64$ year olds versus $30 \%$ in those aged $\geq 75$ years) than men ( $86 \%$ in 50 64 year olds versus $70 \%$ in those aged $\geq 75$ years) as is the increase in being driven by others. Overall, women were almost twice as likely to use public transport as men (11\% versus $6 \%$ ), however use was similar in those aged 75 years and over (9-12\%). 
Figure 3. Mode of transport used most often, by age group and sex

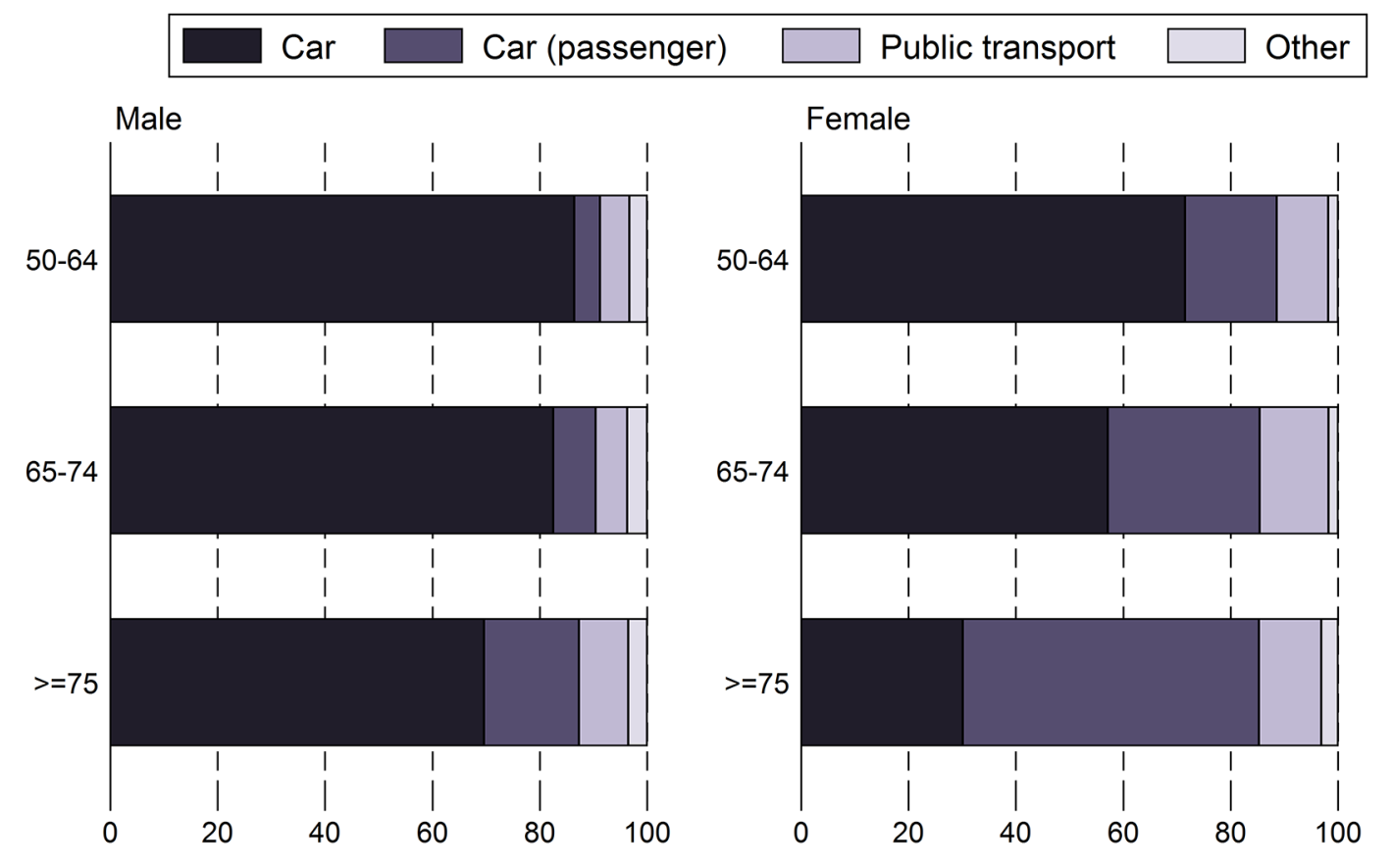

Note. $\mathrm{N}=8092 ;$ Missing obs $=83$

The mode of transport used most often varies with local area (Figure 4). Four out of five adults living in rural areas (78\%) rely mainly on driving themselves compared to $62-65 \%$ of adults in Dublin or other towns and cities. In contrast, only $2 \%$ of those in rural areas and $7 \%$ of those in towns/cities outside of Dublin rely mainly on public transport compared to $24 \%$ of those in Dublin city or county.

There is also a relationship between health status and transport use. Adults with an increasing number of health conditions and progressively poorer self-rated health are less likely to drive themselves and more likely to be driven by others compared to those with fewer conditions and better self-rated health (Figure 5). Those with excellent self-rated health are less likely to use public transport compared to those with fair or good self-rated health (6\% versus $9-11 \%$ ) although the overall levels are relatively low in all groups. 
Figure 4. Mode of transport used most often, by local area

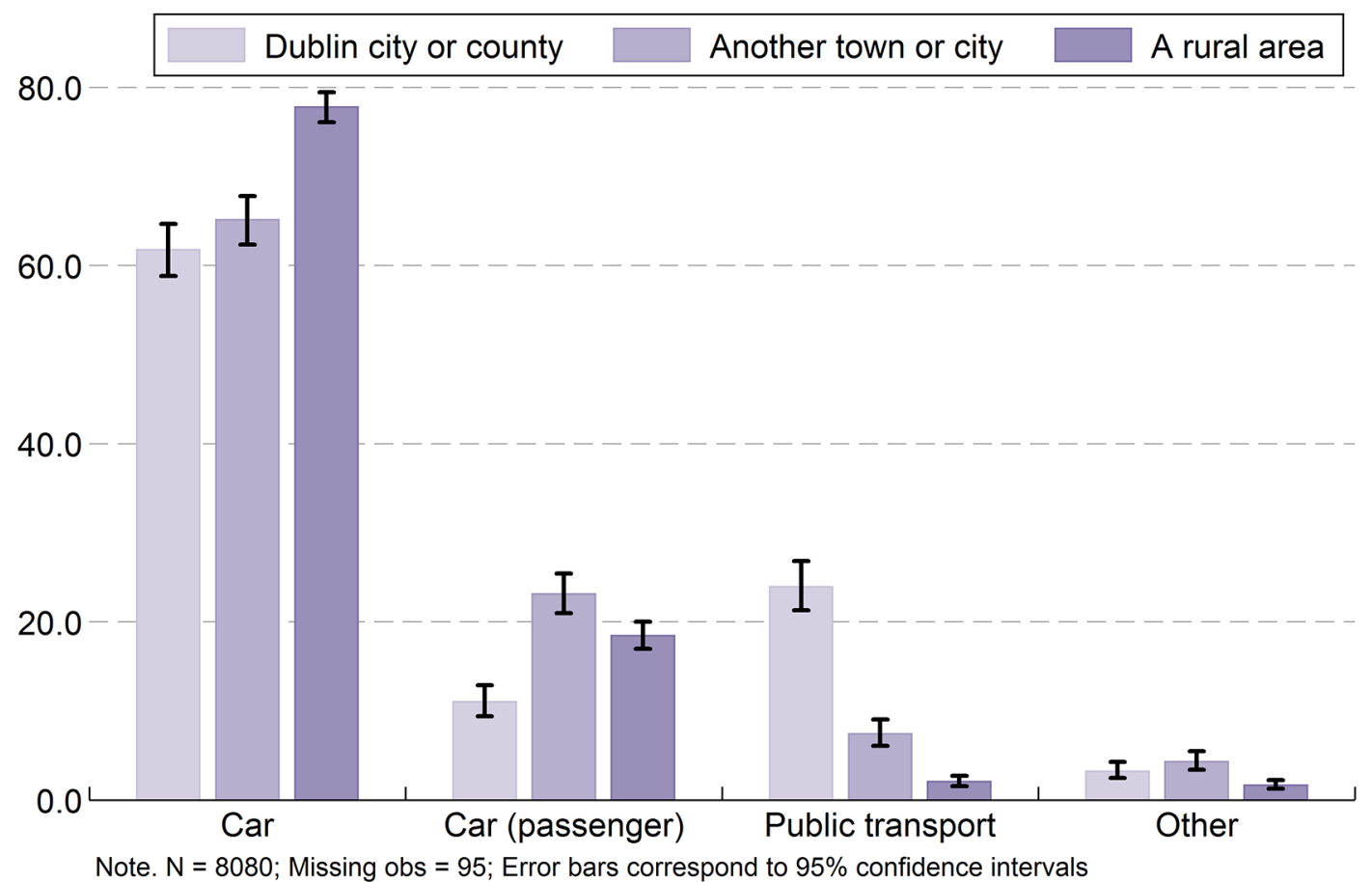

Figure 5. Mode of transport used most often, by self-rated health

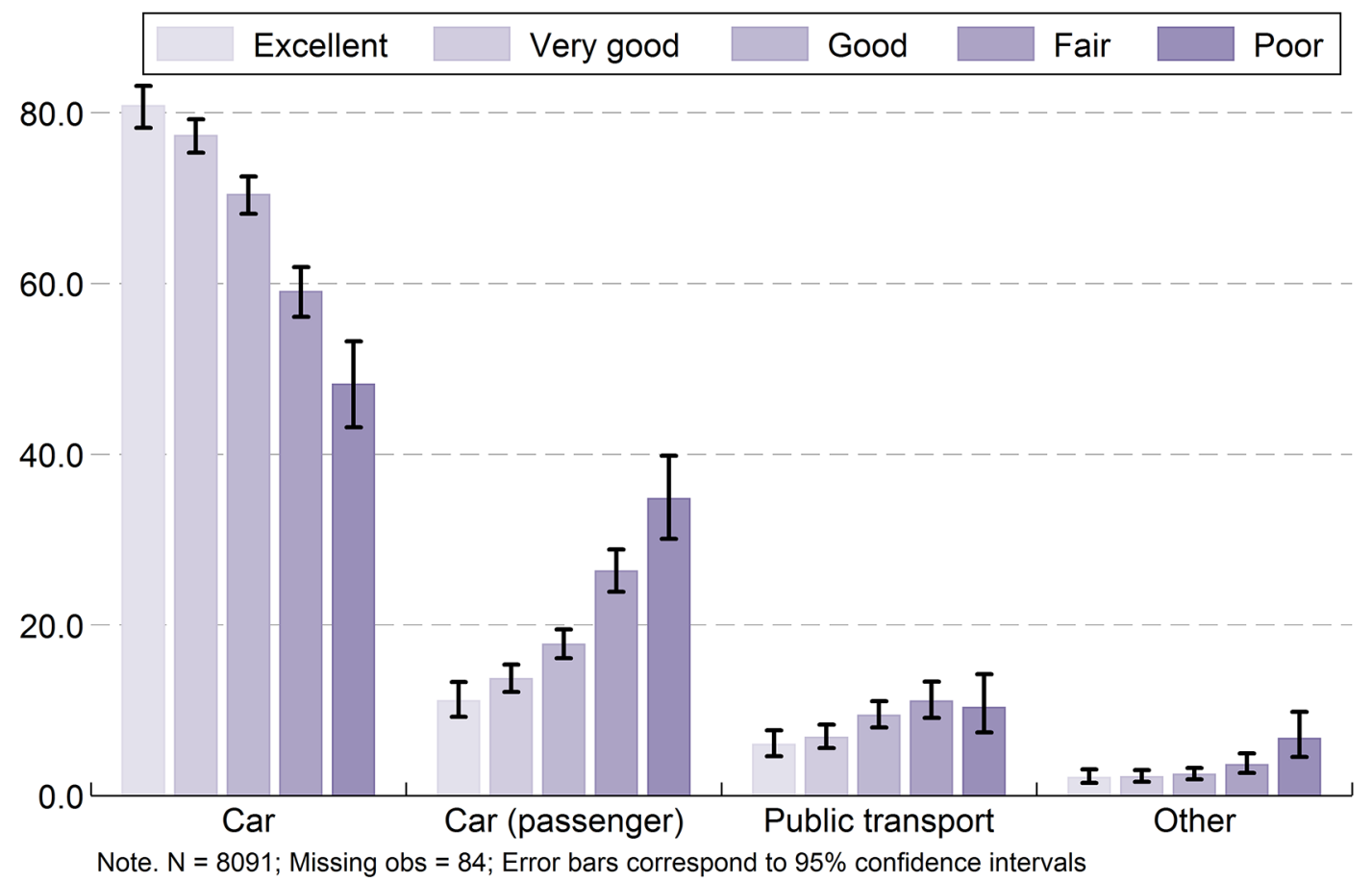




\subsection{Patterns of transport use and social participation}

Participation in leisure activities is an important aspect of an individual's social engagement. In TILDA, social participation is measured using a scale proposed by House et al (1982). Participants were asked to indicate how often they took part in a range of social activities which were categorised into four groups: (i) intimate social relationships (including daily visits to or from family and friends), (ii) formal organisational involvements outside of work (such as going to religious services or meetings at voluntary associations at least once a month), (iii) active and relatively social leisure activities (including going to classes, lectures, movies, plays and concerts, playing cards or bingo, eating outside the house or taking part in sports at least once a month) and (iv) passive and relatively solitary leisure activities (such as watching television, listening to the radio, or reading at least once a month).

The majority of adults aged 50 years and over in Ireland take part in active and social leisure pursuits at least once a month (87\%) while $60 \%$ report involvement in formal organisations outside of work at least once a month. Figure 6 shows that participation in these activities varies with the most frequently used mode of transport. Overall, adults who drive themselves or get public transport were more likely than those relying on lifts from others, to be involved in active and social leisure pursuits (87-91\% versus $76 \%$ ) and formal organisations (56-66\% versus 44\%). However, those relying on lifts from others were more likely to report intimate social relationships (58\%) than the other two groups (44-48\%). Interestingly, this pattern with intimate social relationships was only observed in men (49\% in car passengers versus $33-36 \%$ in those who drive themselves or take public transport). While women are more likely to report intimate social relationships than men are overall, this suggests that men who rely on family or friends for transport have greater opportunities for this type of social engagement.

Volunteering provides social, economic and health benefits and is often viewed as a 'cornerstone of productive ageing' (Lum et al, 2005). In TILDA, voluntary work is assessed by the question 'How often, if at all, do you do voluntary work?' Adults whose main modes of transport are driving or using public transport are more likely to volunteer at least once per month (25-29\%) compared to those relying on others for transport $(15 \%)$, again highlighting the important role that independent travel plays for social participation. 
Figure 6. Social participation, by mode of transport used most often

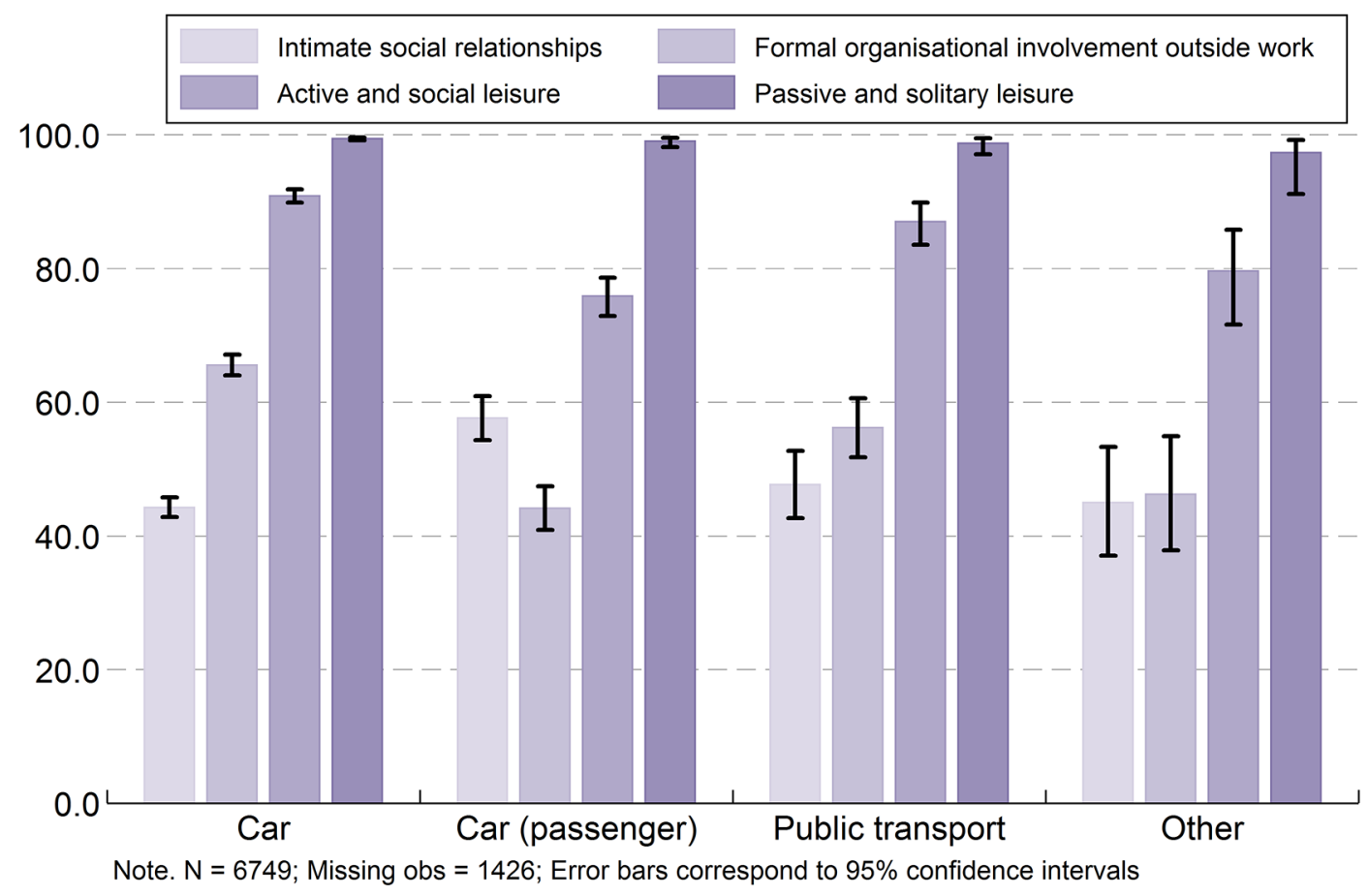




\section{Importance of driving and current driving status}

\subsection{Frequency of driving}

Overall, $75 \%$ of households sampled in TILDA own at least one car, decreasing from $84 \%$ in 50-64 year olds sampled to $49 \%$ in those aged $\geq 75$ years old. Three-quarters of those who drive regularly (i.e. at least twice in the past year), do so every day while $17 \%$ drive between 3 and 6 days per week. Figure 7 shows that both men and women are less likely to drive every day as they get older (men: $85 \%$ of $50-64$ year olds versus $63 \%$ of those $\geq 75$ years old; women: $76 \%$ of $50-64$ year olds versus $53 \%$ of those $\geq 75$ years old).

Figure 7. Frequency of driving during an average week among those who report driving regularly (i.e. at least twice in the last year), by age group and sex

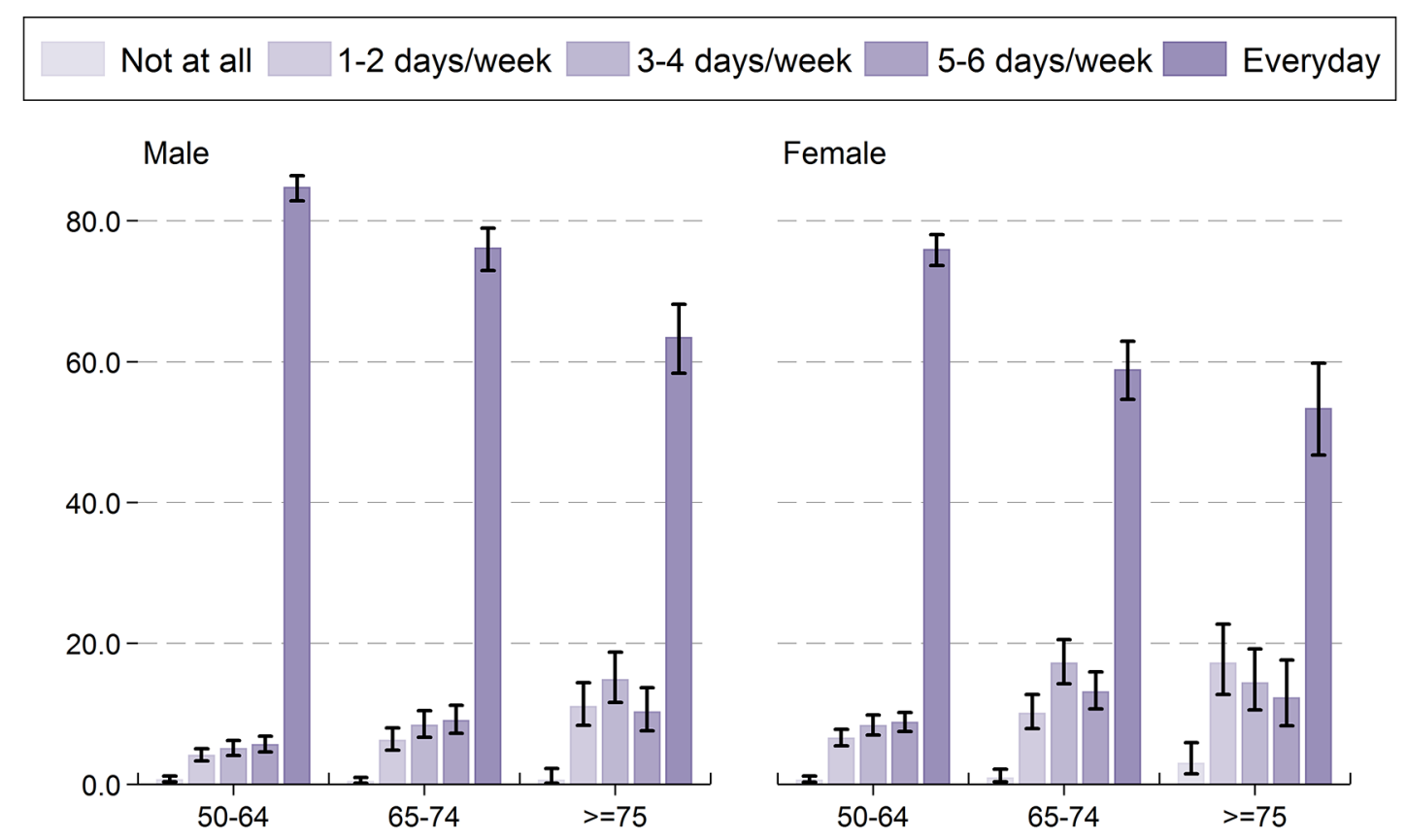

Note. $\mathrm{N}=6212$; Missing obs = 7; Error bars correspond to $95 \%$ confidence intervals 
Over three-quarters of adults who live in rural areas or towns/cities outside of Dublin (76$79 \%$ ) and two-thirds of those living in Dublin (65\%) drive every day. Adults who report better self-rated health and fewer health conditions are also more likely to drive every day i.e. $77 \%$ of those with excellent/very good/good health versus $65 \%$ of those with fair/poor health; $81 \%$ of older adults with no health conditions versus $67 \%$ of those with $\geq 3$ health conditions.

\subsection{Current driving status}

Current drivers (i.e. those who drove at least twice in the past year) were asked if they drive less now compared to five years ago while participants who were not classified as current drivers (i.e. those who did not drive at least twice in the past year) were asked if they used to drive in the past. One-third of current drivers (33\%) report a reduction in their driving frequency in the past five years and this is more common in men (36\% versus $30 \%$ in women) and in the oldest age group ( $50 \%$ of those aged $\geq 75$ years versus $26 \%$ of 50 64 year olds). Of the non-current drivers, $31 \%$ reported that they used to drive in the past and this was more commonly reported in men ( $52 \%$ of men; $23 \%$ of women). Of those who used to drive in the past but are no longer driving, $34 \%$ indicated that they have a valid driver's licence while $18 \%$ are currently insured to drive.

Participants who indicated that they had ceased driving or reduced their driving frequency were given a list of possible reasons for doing so and asked to select the reasons that applied to them. Almost half indicated a 'non-health related reason' for their change in driving habits (49\%) although this became less common with increasing age $(60 \%$ in 50-64 years olds versus $40 \%$ in those aged 75 years and over). In contrast, the most frequent reason in the oldest age group was that they no longer wanted to (38\%). Physical incapacity and problems with vision, hearing or memory were most common in the oldest age group (Figure 8). 
Figure 8. Reasons given for reducing frequency of or ceasing driving, by age group

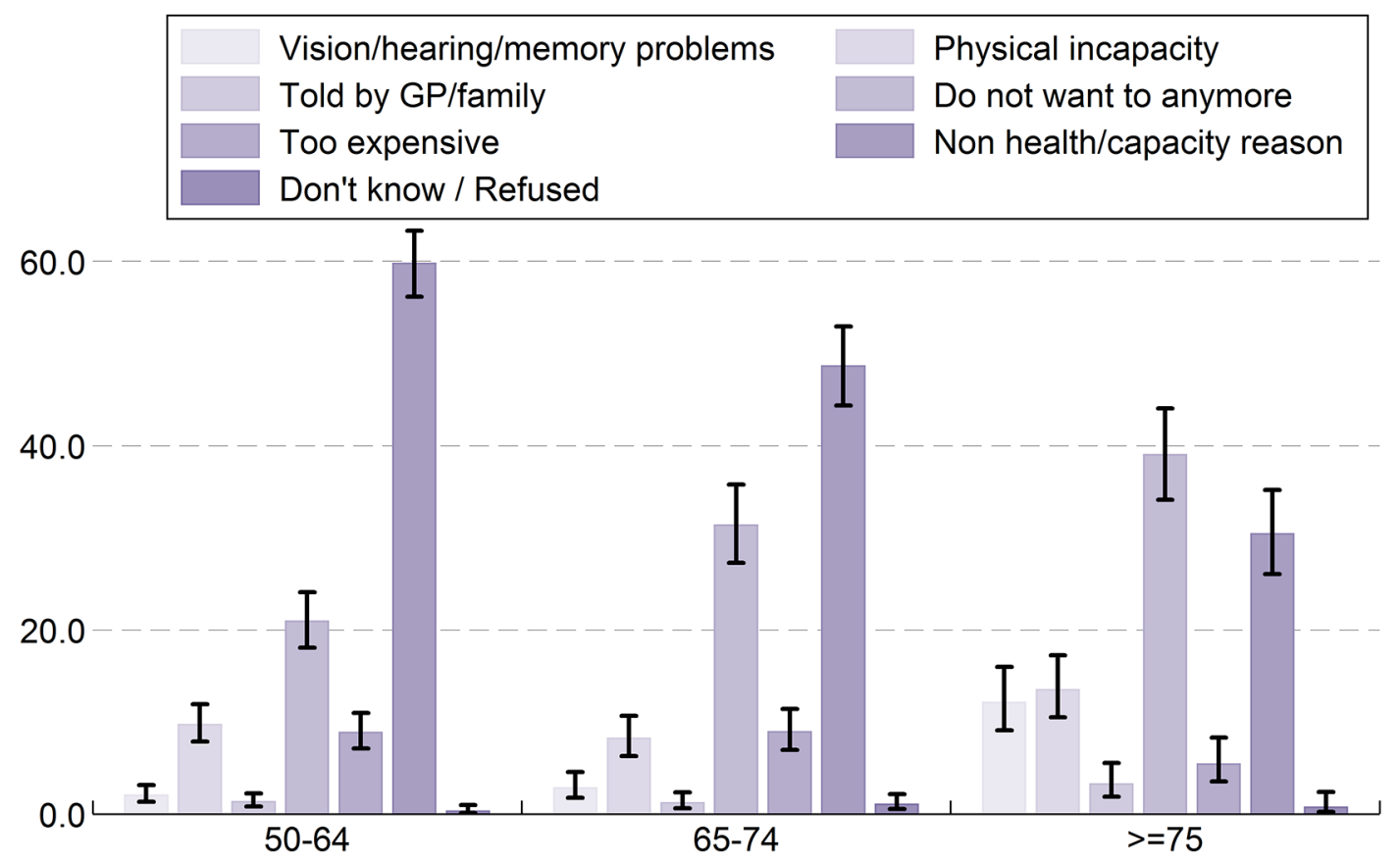

Note. $\mathrm{N}=2679$; Missing obs = 0 ; Error bars correspond to $95 \%$ confidence intervals

\subsubsection{Impact of current driving status on mental health and wellbeing}

In this section, participants are classified into categories that define their driving status: as current drivers, current drivers who drive less than they used to five years ago, previous drivers who no longer do so and non-drivers (i.e. those who have never driven).

Previous research has shown that cessation of driving in older age is associated with a range of adverse outcomes but particularly with increased depressive symptoms (Chihuri et al, 2016). In TILDA, depressive symptoms were measured using the Centre for Epidemiologic Studies Depression (CES-D) scale. This is a 4 point scale where participants rate how often they experienced each of 20 depressive symptoms over the past week (Radloff, 1977). Non-drivers and previous drivers score higher on the CES-D scale and therefore have higher levels of depressive symptoms compared to current drivers (8 versus 5-6). This difference is most notable in those aged 50-64 years where non-drivers and previous drivers score up to 10 on the CES-D scale. While the overall levels of depressive symptoms are low, female drivers report higher levels of depressive symptoms compared to men (Figure 9). 
Figure 9. CES-D score (reflecting level of depressive symptoms), by driving status and sex

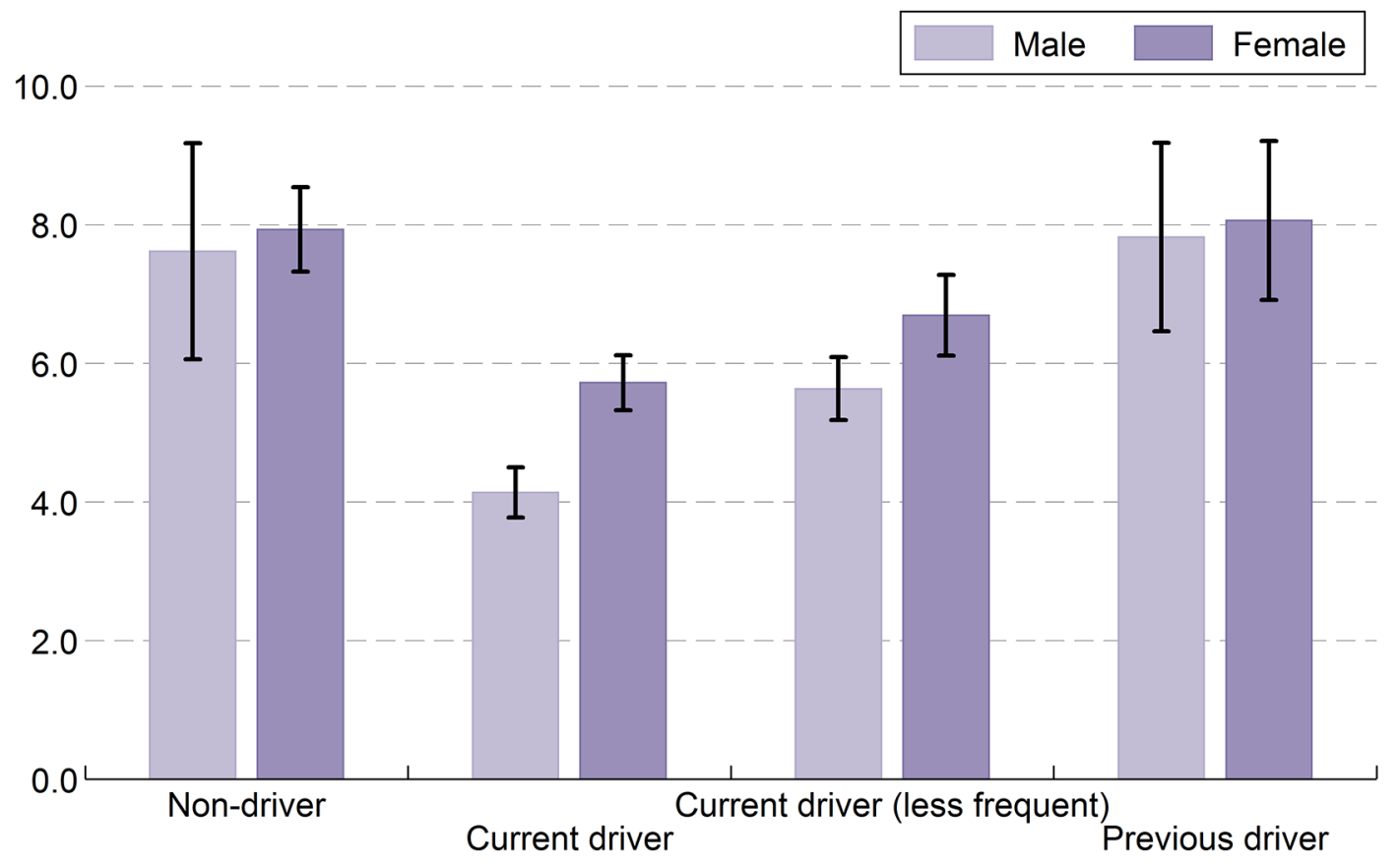

Note. $\mathrm{N}=8041$; Missing obs $=134$; Error bars correspond to $95 \%$ confidence intervals

Quality of life reflects the general wellbeing of an individual and is measured in TILDA using the CASP-19 scale. This includes 19 items that cover four main areas: control (the ability to actively participate in one's environment), autonomy (the right of an individual to be free from the unwanted interference from others), self-realisation (the fulfilment of one's potential) and pleasure (the sense of happiness or enjoyment that one derives from engaging with life). Item scores are summed to give an overall score ranging from 0-57, with higher scores indicating better quality of life (Hyde et al, 2003). Current drivers, including those who drive less than they used to have higher CASP-19 scores compared to previous drivers and non-drivers (43-45 versus 41 ) indicating better quality of life. There is evidence of an age-related effect with adults aged 65-74 years reporting highest quality of life compared to the other age groups in the current and previous driver groups.

Loneliness reflects 'an individual's evaluation of their overall level of social interaction, and describes a deficit between the actual and desired quality and quantity of social engagement' (Victor et al, 2005). It has been associated with declines in physical, mental and cognitive health in older adults (Hawkley and Cacioppo, 2010). In TILDA, loneliness was measured using a modified version of the University of California-Los 
Angeles (UCLA) Loneliness scale (Russell, 1996). This version includes five items, each with three response options (hardly ever or never, some of the time, often). Responses were summed with the overall score ranging from 0 (not lonely) to 10 (extremely lonely). Current drivers (including those who drive less frequently than five years ago) have lower loneliness scores compared to previous drivers and non-drivers (1.8-2.1 versus 2.5-2.7) (Figure 10). This is similar in men and women of all ages.

Figure 10. UCLA-Loneliness score (reflecting symptoms of loneliness), by driving status

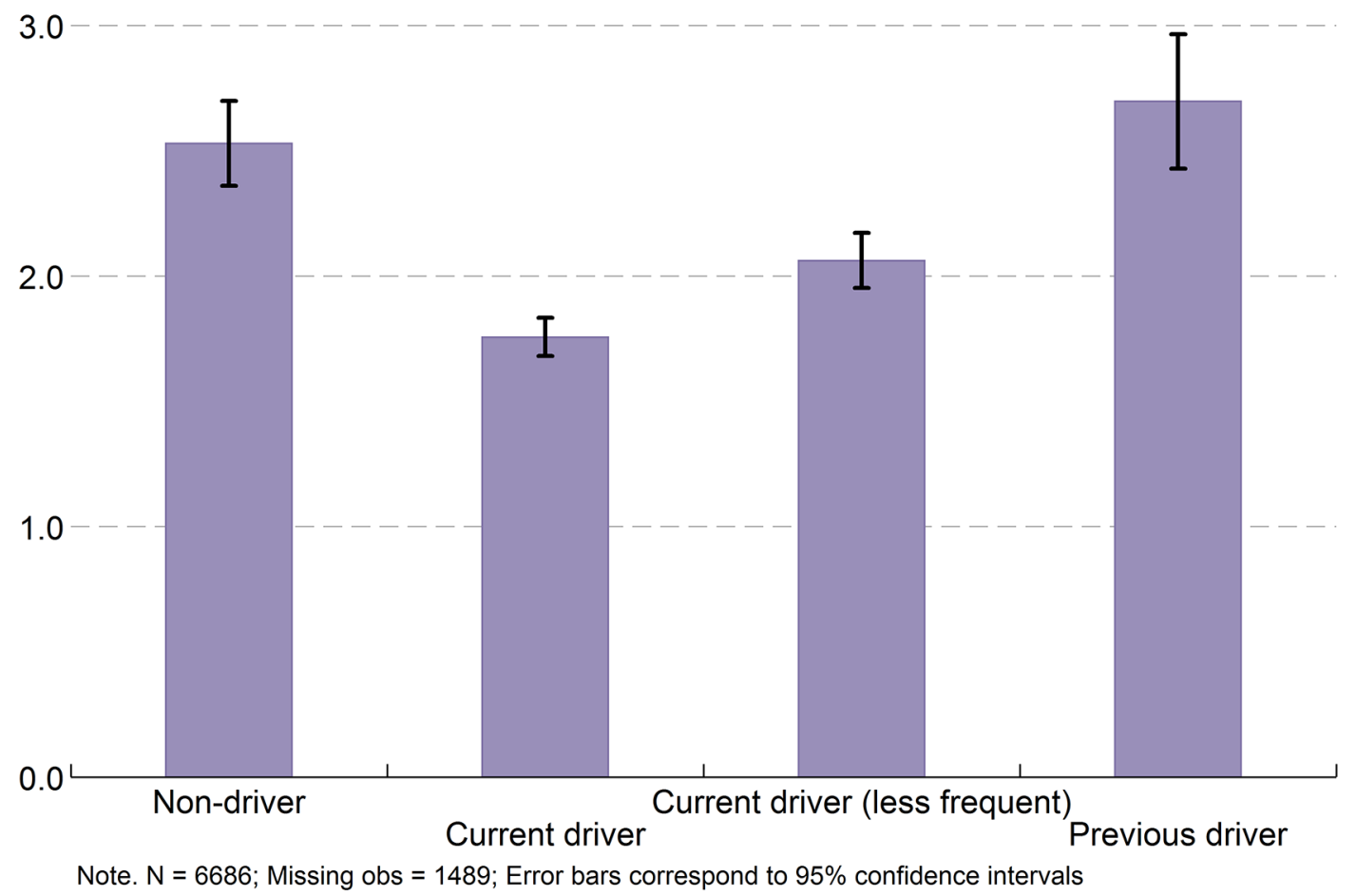

\subsubsection{Impact of current driving status on social participation}

Driving status also has an impact on social participation (Figure 11). Current and previous drivers are more likely to report active social participation compared to non-drivers (84$92 \%$ versus $74 \%$ ). However, current drivers are more likely to be involved in formal organisational activities (63-66\%) compared to both previous drivers $(52 \%)$ and nondrivers (43\%). Intimate social relationships were highest in the non-drivers and previous drivers, possibly reflecting increased social interactions when relying on public transport or family or friends for lifts. Current drivers were more likely to volunteer at least once per month (29\%) compared to previous drivers (20\%) and non-drivers (17\%). 
Figure 11. Social participation, by driving status

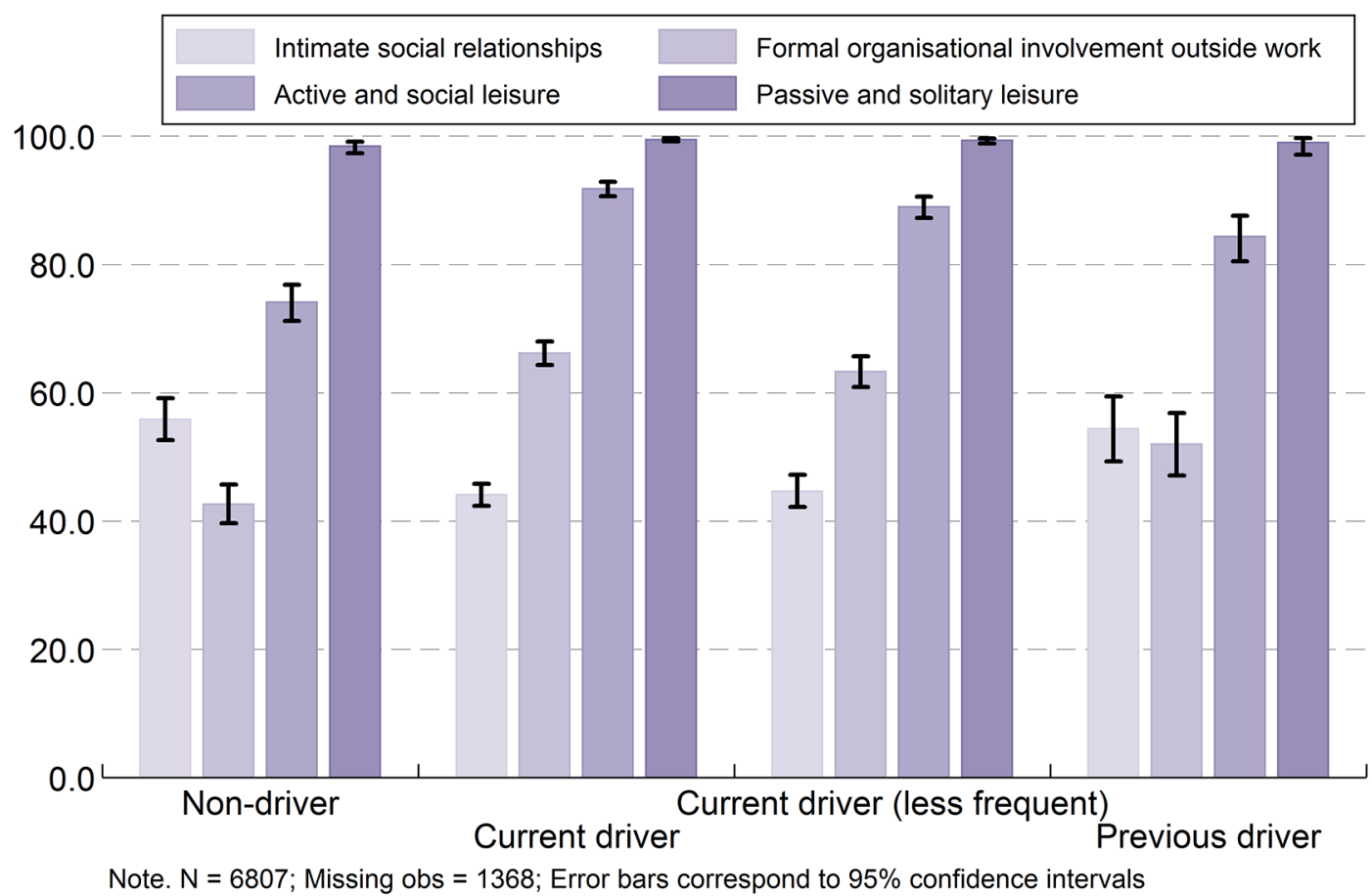

Further information, specifically about the impact of driving cessation or reduction, was obtained by asking participants who reported that they were not driving or had reduced driving over the past 12 months, if it had affected their daily activities. Specifically they were asked if it affected how they socialise with others (e.g. visiting family and friends), their ability to go about their business (e.g. doing the shopping, going to the post-office, visiting the bank, attending the church etc.) and their ability to attend health and social care appointments (e.g. out-patient clinics at the hospital). Almost one in eight people (13\%) reported that driving reduction or cessation affected their socialising 'some, most, or all of the time' in the past 12 months; it also affected their business-related activities (10\%) and their health/social care activities (7\%). Figure 12 shows that a greater proportion of those aged 75 years and over report activity restriction across all domains, and the disparity between age groups is particularly apparent for health and social care appointments (11\% of the oldest age group affected compared to $5 \%$ of $50-64$ year olds). 
Figure 12. Proportion who report that driving reduction or cessation impacts on socialising, business-related activities or health/social care activities, by age group

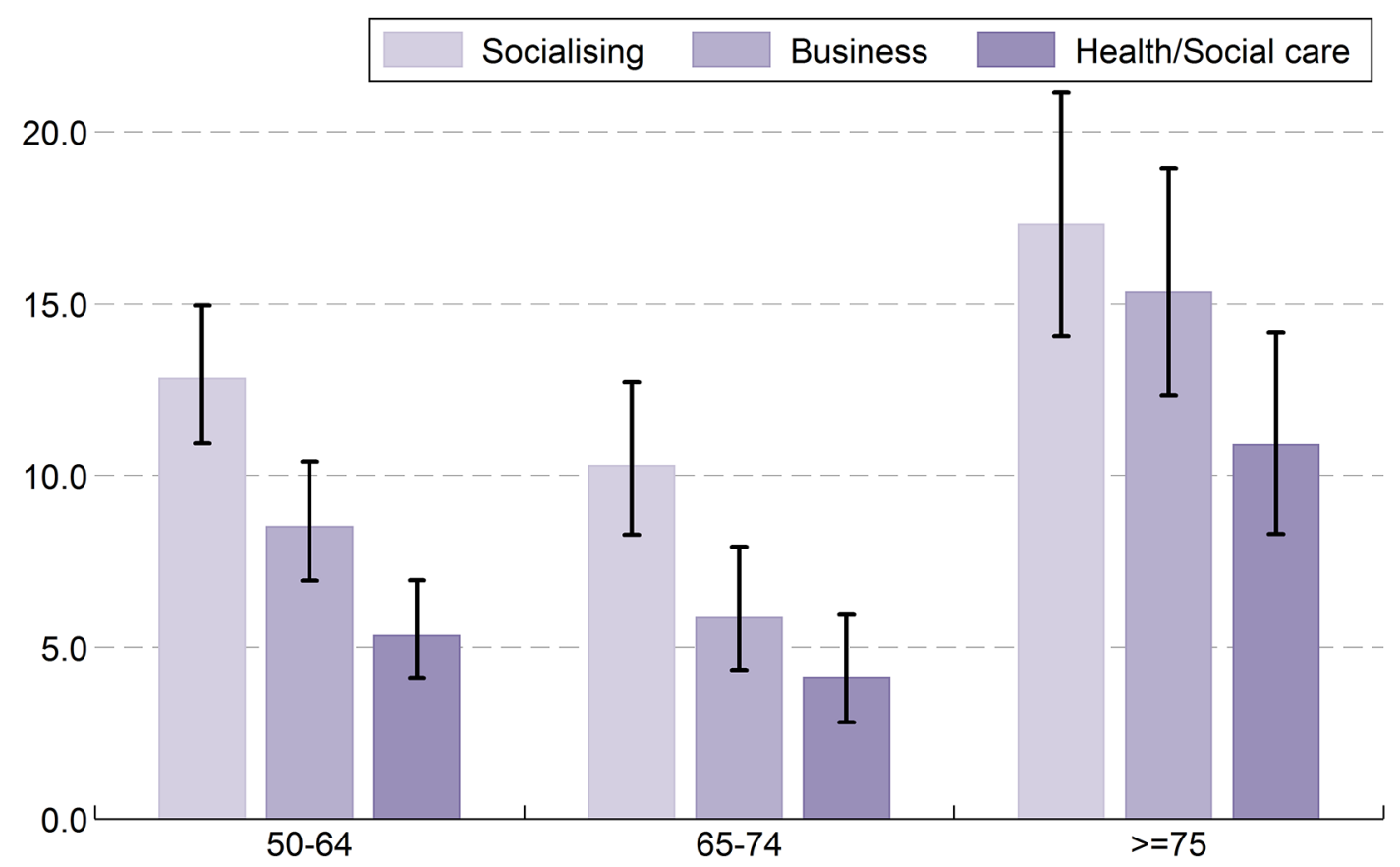

Note. $\mathrm{N}=2675$; Missing obs = 7; Error bars correspond to $95 \%$ confidence intervals 


\section{Evaluation of public and private transport options}

\subsection{Possession of a Free Travel Pass}

In Ireland, free travel passes allow for travel on state public transport services, including buses, rail and the Luas (Dublin-based tram system). They are available to adults aged 66 years and over, and to individuals in receipt of some disability allowances. Carers, spouses or companions travelling with the travel pass holder may also travel for free. Overall, nearly half of adults aged 50 years and over living in Ireland (48\%) have a travel pass, and as expected, this is highest in the older age groups with $88 \%$ of $65-74$ year olds and $98 \%$ of those aged 75 years and over having a travel pass (Table 2). Possession of a travel pass is similar in men and women over 65 years, however women aged 50-64 years are more likely to have a travel pass than men, possibly as they are more likely to have spouses aged 66 years and over.

Table 2. Possession of a Free Travel Pass, by age group and sex

\begin{tabular}{|c|c|c|c|c|c|c|c|c|}
\hline & \multicolumn{2}{|c|}{50 to 64 years } & \multicolumn{2}{|c|}{65 to 74 years } & \multicolumn{2}{|c|}{$\begin{array}{c}75 \text { years and } \\
\text { over }\end{array}$} & \multicolumn{2}{|c|}{ Total } \\
\hline & $\%$ & $95 \% \mathrm{Cl}$ & $\%$ & $95 \% \mathrm{Cl}$ & $\%$ & $95 \% \mathrm{Cl}$ & $\%$ & $95 \% \mathrm{Cl}$ \\
\hline Men & 11 & {$[9-12]$} & 86 & [84-88] & 98 & [96-99] & 45 & [43-47] \\
\hline Women & 18 & [16-19] & 89 & [86-91] & 98 & [97-99] & 51 & [49-53] \\
\hline Total & 14 & [13-15] & 88 & [86-89] & 98 & [97-99] & 48 & {$[47-50]$} \\
\hline
\end{tabular}

Adults with a free travel pass are more likely to use buses regularly (at least twice in the previous year) compared to those without a pass (28\% versus $20 \%$ ) and more likely to travel as a passenger in a car $(61 \%$ versus $32 \%)$ rather than driving themselves $(61 \%$ versus $86 \%$ ) (Figure 13). The proportion of men and women with a free travel pass who have used both buses and trains in the past year is similar. While the overall proportion of adults for whom public transport is their main mode of transport is low, almost twice as many adults with a free travel pass indicate this compared to adults without a travel pass ( $11 \%$ versus $6 \%$ ). However, the car remains the most frequently used mode of transport in the vast majority of older adults with and without a free travel pass ( $86 \%$ and $91 \%$ 
respectively). As shown previously, adults living in Dublin are more likely to report that they use public transport most often compared to those living in other towns/cities or rural areas. Almost one in three Dublin-based adults with a free travel pass use public transport (29\%) compared to just $10 \%$ of adults in other towns/cities and $3 \%$ of those living in rural areas. This suggests that while the free travel pass may be an incentive to use public transport, the services available particularly in rural areas, may not meet the needs of older adults who must then rely on a car for their travel. For a substantial proportion of adults, a free travel pass therefore seems to have limited benefit.

Figure 13. Modes of transport used regularly (i.e. at least twice in the past year), by possession of a free travel pass

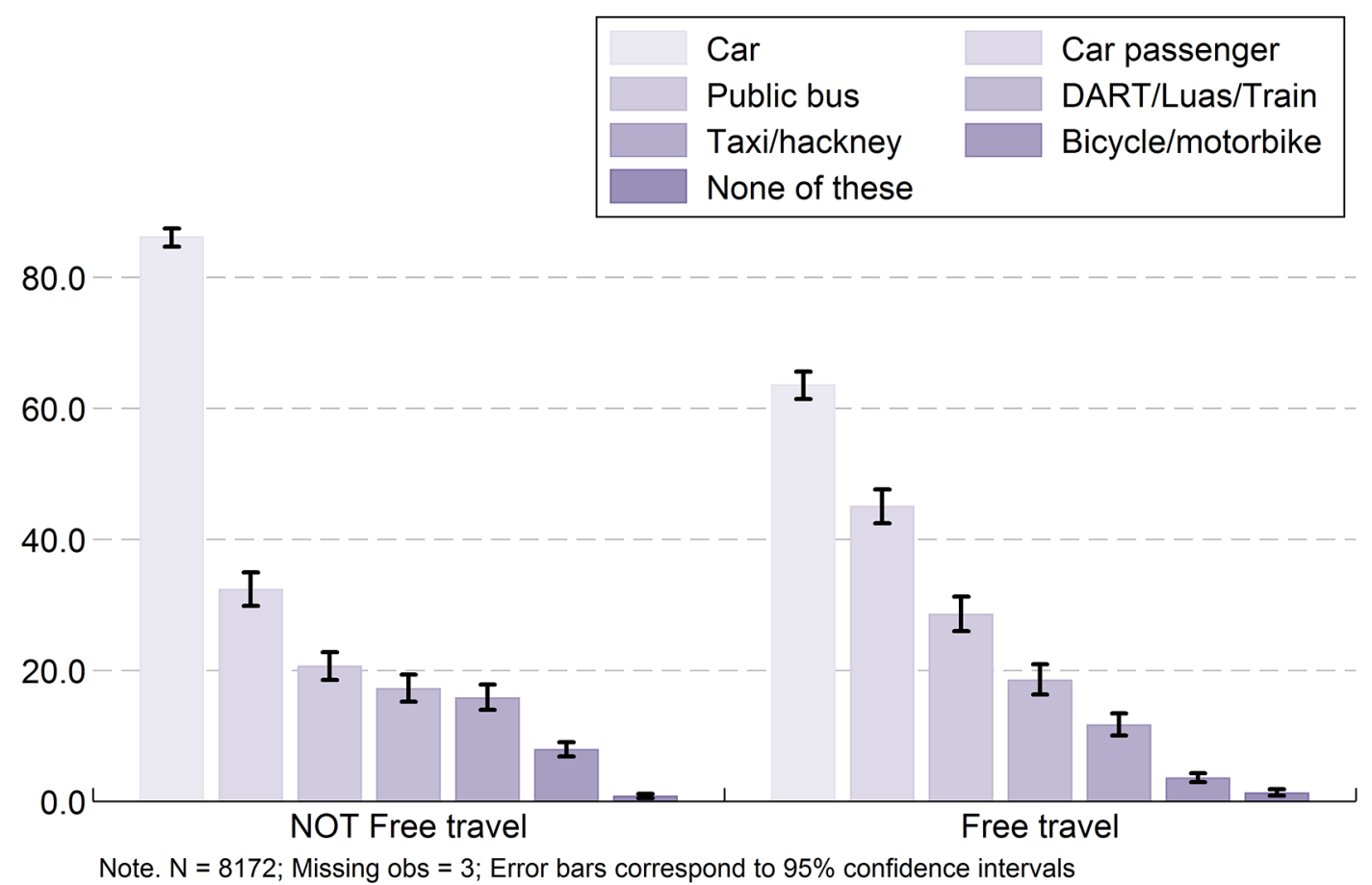

Adults with a free travel pass were asked to estimate how much they had saved in the last four weeks through using it. A large proportion (70\%) indicated that they had not made any savings from using their pass, suggesting that many older adults do not avail of public transport services even if they have access to a travel pass.

Of the $29 \%$ who reported savings through use of a travel pass, almost half live in Dublin city or county (45\%), $28 \%$ live in other towns/cities and $27 \%$ live in rural areas. The average saving over the past four weeks was $€ 48$. Although those in Dublin were more likely to save money with a travel pass, they saved less $(€ 36)$ compared to those living in 
other towns/cities and rural areas (€58). This likely reflects the lower prices of local buses, trams and trains in Dublin compared to travel to neighbouring towns or villages in more rural areas.

\subsection{Evaluation of public and private transport options}

Participants were asked to rate the public transport options (trains, public buses and community buses) in their neighbourhood as one of the following five options: very poor, poor, fair, good or excellent. Nearly half (49\%) rated their local public transport options as good/excellent, however $36 \%$ rated them as poor/very poor. This varied substantially by local area with $81 \%$ of adults in Dublin city/county rating public transport options as good/ excellent compared to $25 \%$ of those living in rural areas (Figure 14). Three in five adults in rural areas $(58 \%)$ rated their public transport options as poor or very poor. There was little difference between age groups and sex.

Figure 14. Rating of public transport options, by local area

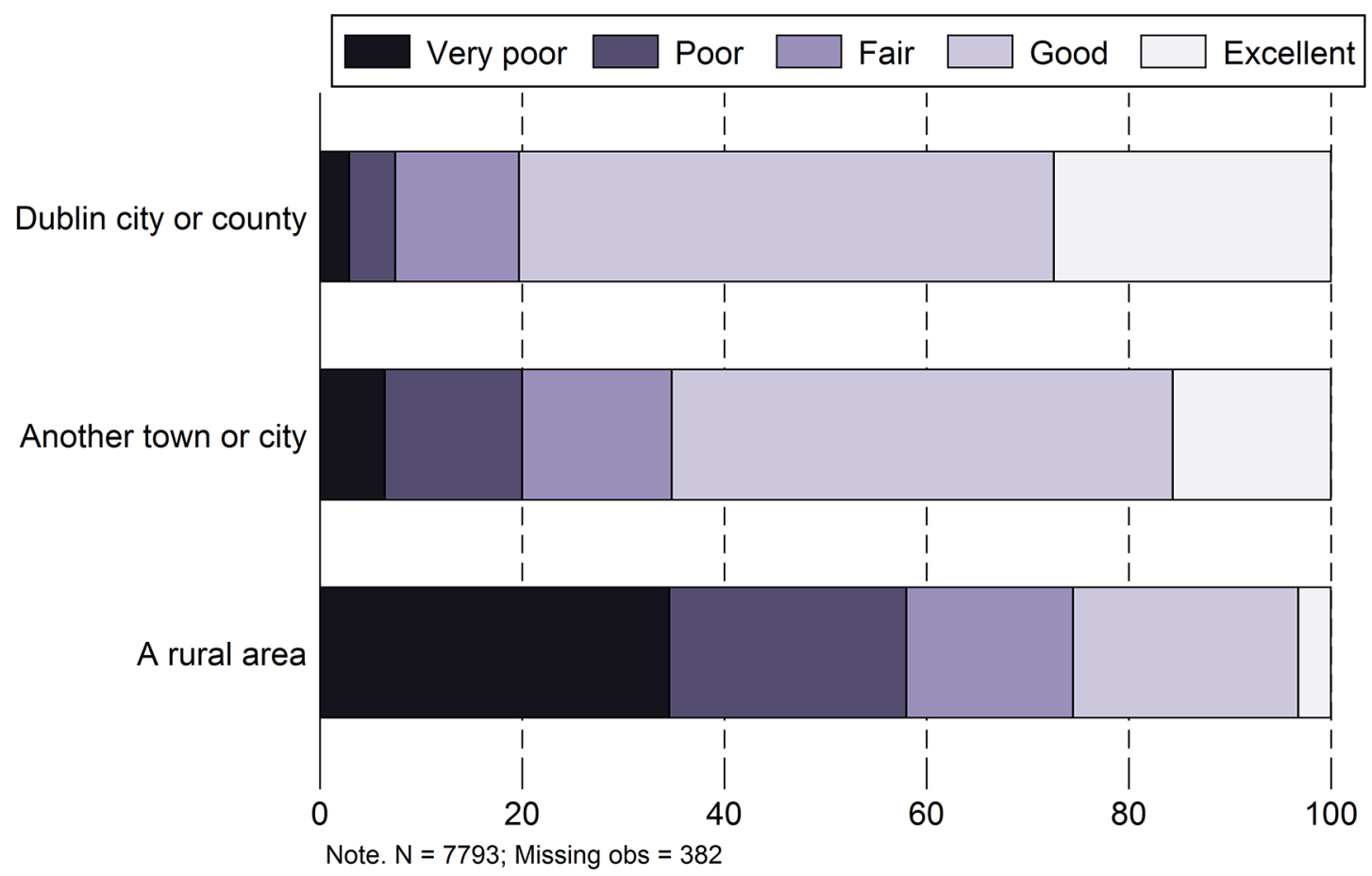

Participants were also asked if the lack of public transport facilities in their local area affected their lifestyle and to what extent. Answer options were recoded into two categories: 'affected to any extent' (i.e. affected a great deal or to some extent), and 'not at all affected'. While most adults (90\%) felt that their lifestyle was not affected, those who are 
affected are more likely to be older ( $12 \%$ in those aged $\geq 75$ years versus $9 \%$ in $50-64$ year olds) and living in rural areas (13\% versus $5-7 \%$ of those in Dublin or other towns/cities). The lifestyles of adults aged 75 years and over living in rural areas are most affected $(19 \%)$, compared to adults of the same age living in Dublin or other towns/cities (5-8\%).

Whether the lifestyles of adults aged 50 years and over are affected by the lack of public transport options varies with the mode of transport used most often (Figure 15). Two in five adults (39\%) who use taxis as their main mode of transport report being affected, highlighting the lack of alternative transport options and the need to use what is often the most expensive option. In addition, $7 \%$ of those who drive themselves and $13-16 \%$ of those who travel as a car passenger or by public transport are negatively affected highlighting that there is room for improvement.

Figure 15. Proportion of adults affected by lack of local transport options, by mode of transport used most often

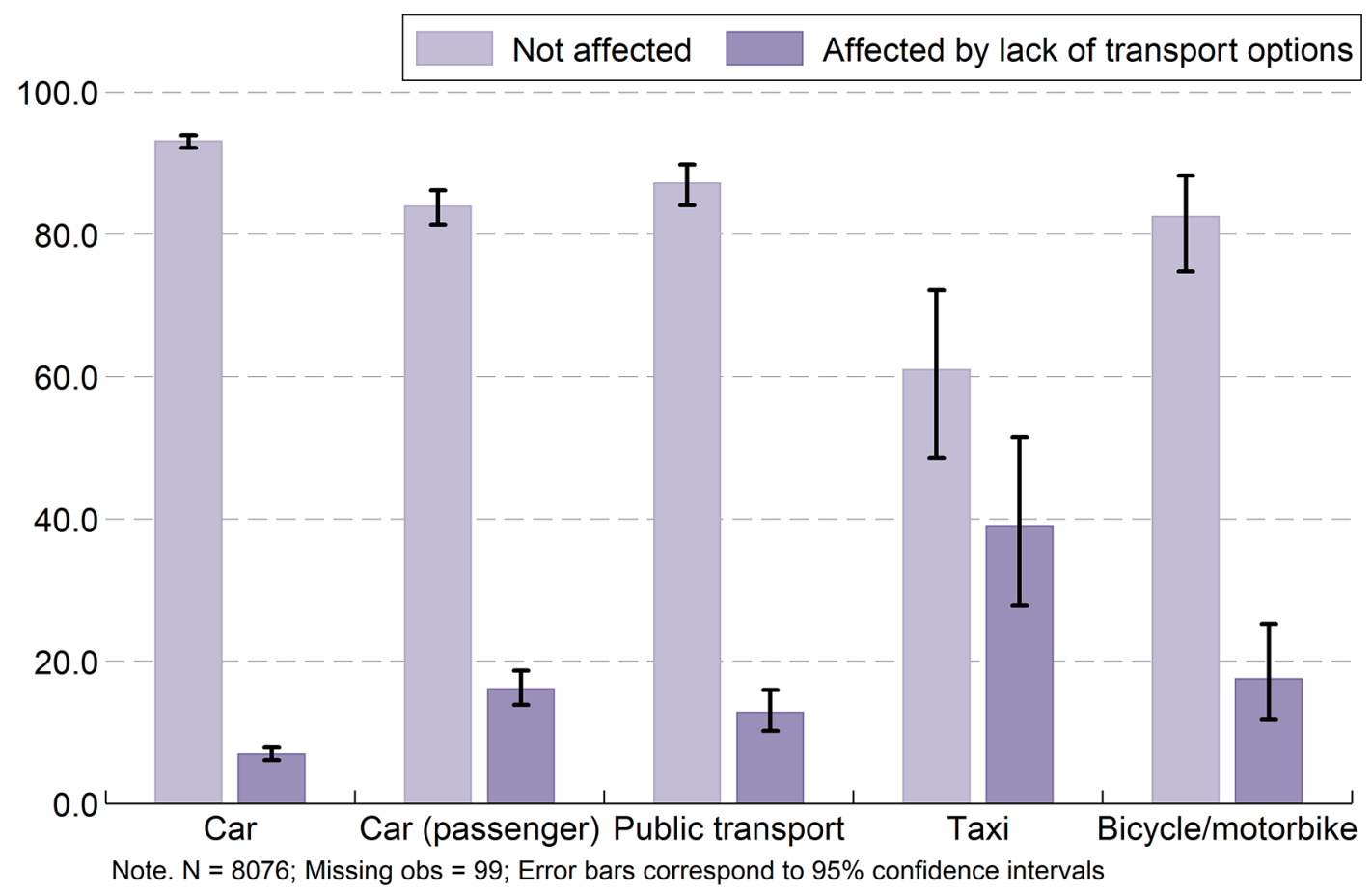

Adults in poorer health were more likely to report their lifestyle being affected by a lack of transport options. Only $7 \%$ of those who self-rated their health as excellent reported being affected compared to $20 \%$ of those who self-rated their health as poor. The effect was similar although less pronounced when looking at the number of health conditions; $8 \%$ of those with no health conditions reported their lifestyle being affected compared to $12 \%$ of 
those with three or more conditions.

Participants were asked to rate the private transport options (taxis, hackneys) in their neighbourhood as one of the following five options: very poor, poor, fair, good or excellent. Almost two-thirds of the population $(62 \%)$ rated their private transport options as excellent or good, while $24 \%$ rated them as poor or very poor. While $90 \%$ of adults in Dublin city/ county rated private transport as good/excellent, only $34 \%$ in rural areas did so.

\subsection{Suggested improvements to public transport}

Participants were asked what they consider to be the most important improvements that could be made to the transport options available to them. Answers were recorded in free text form by interviewers, and subsequently re-coded into the following categories: suggested improvements relating to public (state) or private (taxis and private transport companies) transport in their local areas (e.g. different routes, increased frequency of service, improved quality of service), other improvements (e.g. better roads, resolving issues around bike and bus lanes, the cost of driving and parking options), no improvements required, and don't know.

Two in five adults (43\%) mentioned improvements that could be made to public or private transport in their local areas while $5 \%$ suggested other improvements. Over one-third $(36 \%)$ felt that they didn't know or could not say, in most cases as they did not use these forms of transport while 15\% were happy with the options available to them and felt that no changes were required. Adults aged 75 years and over were less likely to suggest improvements than those aged $50-64$ years (34\% versus $47 \%$ ) but more likely to indicate that they didn't know (45\% versus $33 \%$ ), possibly due to reduced use of these services.

The proportion of adults suggesting improvements to public and private transport options also varied by local area (Table 3). Almost half of adults in Dublin city/county and rural areas mentioned improvements while those in other towns/cities were most likely to say that no improvements were needed ( $21 \%$ versus $15 \%$ in Dublin and $12 \%$ in rural areas). 
Table 3. Suggested areas for improvement, by local area

\begin{tabular}{|l|c|c|c|c|c|c|c|c|} 
& $\begin{array}{c}\text { Dublin } \\
\text { county/city }\end{array}$ & \multicolumn{2}{c|}{$\begin{array}{c}\text { Another } \\
\text { town/city }\end{array}$} & \multicolumn{2}{c|}{ A rural area } & \multicolumn{2}{|c|}{ Total } \\
\hline & $\%$ & $\mathbf{9 5 \%} \mathbf{C l}$ & $\%$ & $\mathbf{9 5 \%} \mathbf{~ C l}$ & $\%$ & $\mathbf{9 5 \%} \mathbf{~ C l}$ & $\%$ & $\mathbf{9 5 \%}$ Cl \\
\hline Public transport & 46 & {$[43-48]$} & 33 & {$[31-35]$} & 48 & {$[47-50]$} & 43 & {$[42-44]$} \\
\hline Other & 4 & {$[3-4]$} & 7 & {$[6-8]$} & 4 & {$[4-5]$} & 5 & {$[4-5]$} \\
\hline No improvement needed & 15 & {$[13-17]$} & 21 & {$[20-23]$} & 12 & {$[11-13]$} & 15 & {$[14-16]$} \\
\hline Don't know / not applicable & 31 & {$[28-33]$} & 39 & {$[37-41]$} & 36 & {$[34-37]$} & 36 & {$[34-37]$} \\
\hline
\end{tabular}

The suggested improvements to public and private transport options were broken down further into the following categories: cost or experience; routes or availability; and frequency or timing. The majority of suggested improvements relate to routes and availability (47\%) and frequency and timing (41\%), however these suggestions vary depending on local area (Figure 16). Adults living in Dublin city or county are more concerned with the frequency or timing of public transport (e.g. buses not running on time, bus and train times being unsuitable for their needs, timetables being unreliable), and the experience of using public transport (e.g. cost, wheelchair access, steep steps to get onto buses and trains, or unpleasant drivers) than those living in other parts of the country. In contrast, those in rural areas are more concerned with availability of transport and appropriate transport routes. Recurring themes for those in rural areas are the lack of bus routes, closure or threatened closure of existing bus routes and the need to walk long distances to catch a bus. Notably, those in rural areas also have issues with the timing and frequency of their local public transport, in particular mentioning village buses which only pass once a week, inconvenient timetables for shuttle buses into local towns, or transport options which stop running after a certain time. These limit socialising opportunities such as going out for dinner or to the pub. Table 4 provides examples of suggested improvements to public transport in Dublin and rural areas. 
Figure 16. Specific areas of public and private transport services requiring improvement, by local area

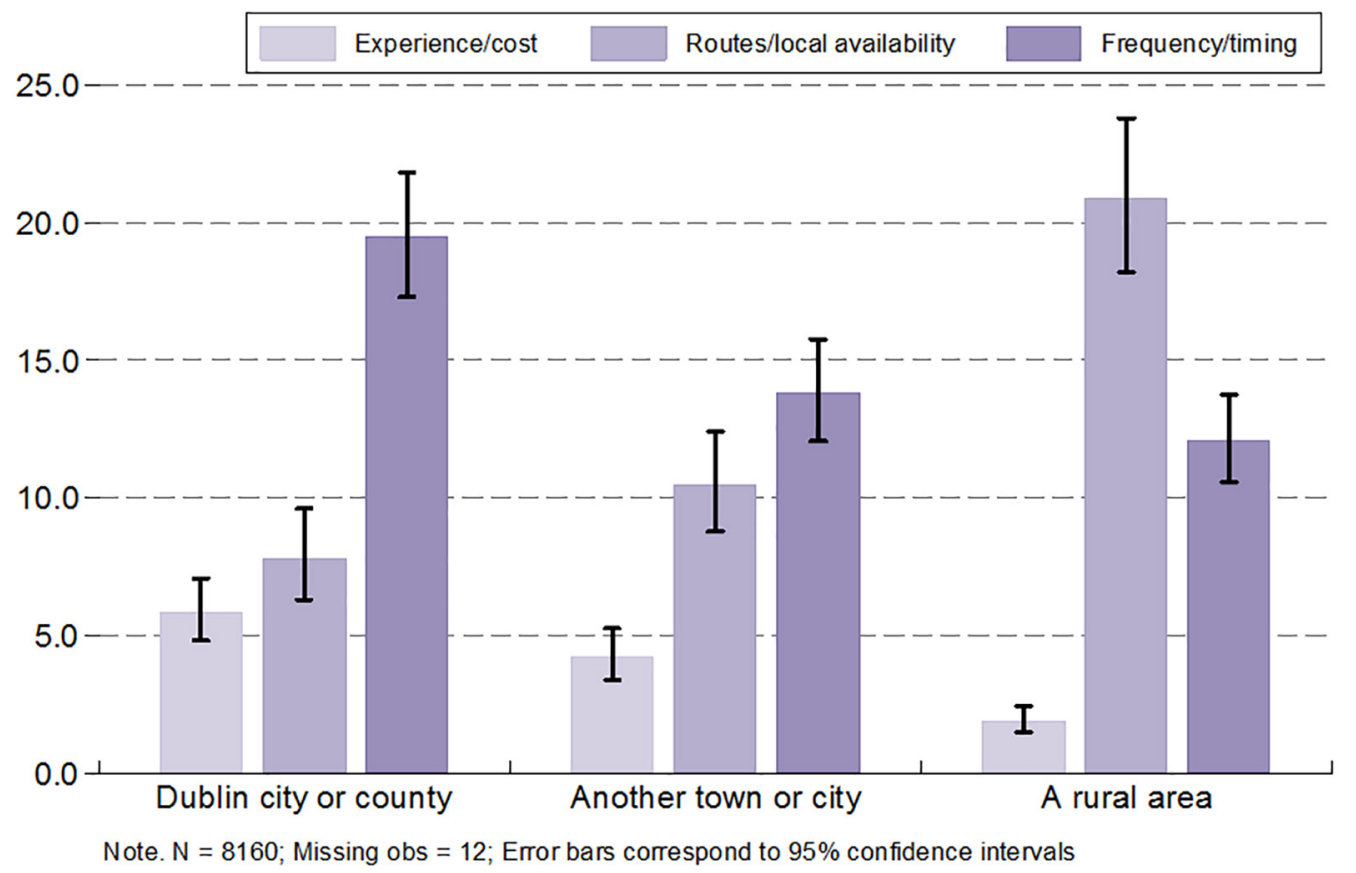

Table 4. Examples of suggested improvements to public transport in Dublin and rural areas

\section{Suggested improvements (Dublin)}

"[We need] better roads, better footpaths suitable for wheelchair users, [and] more buses for wheelchair users"

"[An] integrated system, with more accessible bus service, smaller frequent buses serving the Luas and the DART, more accessible transport off peak, run in conjunction with all the services"

"Could improve schedules, [the timing of the buses] could be more reliable. Two arrive at the same time and then you are waiting around for ages"

\section{Suggested improvements (rural areas)}

"A local bus service from near my house into town - at the moment have to walk 3 miles in order to get a bus and they only come twice a day"

"A bus service would be nice... there used to be one years ago"

"Rural bus service. I run a pub so it would help my business if people did not have to drive" 


\section{Conclusions}

Population demographics are changing rapidly with a substantial increase in the proportion of older adults projected for the coming years. This report shows that the car is the main mode of transport for $89 \%$ of adults aged 50 years and over in Ireland while less than one in ten $(9 \%)$ rely on public transport. As people (especially women) get older, they are less likely to drive themselves and more likely to rely on lifts from others. Use of public transport increases only marginally with age, which may reflect a combination of both greater convenience when travelling by car and the lack of suitable public transport options available.

One in five adults aged 75 years and over living in rural areas (19\%) indicate that the lack of local transport facilities affects their lifestyle. $12-18 \%$ of the same age group indicate that reduced frequency of driving or no longer driving affects their ability to socialise, attend business-related appointments and health/social care appointments. Previous research has shown that while older adults are more likely to seek out transport options and accept lifts for 'serious' medical or food-related trips, they are more likely to forego spontaneous 'discretionary' trips such as socialising in an effort not to burden others or be beholden to them (Davey et al, 2003; Ahern and Hine, 2010).

Continued participation in community and leisure pursuits outside of the home is important for both health and social benefits (House et al, 1988; Siegrist and Wahrendorf, 2009). Adults who drive themselves or who travel mostly by public transport report greater participation in social activities and volunteering compared to those who rely on lifts from others. In addition, non-drivers including those who used to drive in the past report higher levels of depressive symptoms and loneliness and lower quality of life compared to current drivers. However, on a more positive note, non-driving men are more likely to report intimate social relationships compared to current drivers suggesting that their reliance on others for lifts may provide an opportunity for enhanced social interactions with others.

The main mode of transport varies by geographical area with one-quarter of adults living in Dublin city/county relying mainly on public transport compared to just $2 \%$ of adults in rural areas, reflecting the vast differences in transport services available. Many individuals, 
especially those in rural areas, must travel to access key services such as shops, banks, post offices and health and social care services. In recent years, many of these rural services have closed and moved to larger towns and cities. This alters travel requirements and can make it more difficult for those who rely on lifts from others and/or public transport to access these services as regularly and as easily as they once did. In many cases, a car is the only way for these individuals to access these services and interact with others in their communities. Transport services that are available, particularly in rural areas, are often limited in terms of the routes and schedules and therefore do not always meet the needs of older adults. This is supported by the fact that $58 \%$ of adults living in rural areas rate the public transport services in their area as poor or very poor.

Given the geographical spread in many rural areas, it is often not economically viable for companies to provide a service with the same scope as is available in urban areas. However, adults in rural areas still have transport needs, and these change with increasing reliance on others, as they get older. Appropriate transport links should meet the needs of the population that they serve, provide a way for people to maintain their levels of social participation and access the range of services required for an active and independent life, thus leading to improved health and wellbeing.

In Ireland, the National Transport Authority are responsible for managing the Rural Transport Programme, the aim of which is to provide a 'quality nationwide community based public transport system in rural Ireland which responds to local needs' (https://www. nationaltransport.ie/public-transport-services/rural-transport-programme/). This currently provides scheduled public bus services and door-to-door services in local and rural areas and the number of passenger journeys has steadily increased year-on-year reaching over 1.7 million journeys in 2013 (Pobal, 2014). The cited report highlights the success of this scheme and the benefits to its users in terms of social inclusion and quality of life. Other travel options including car sharing schemes (https://www.carsharing.ie/home) and car donations in exchange for travel vouchers (Holley-Moore and Creighton, 2015) highlight the scope for alternative means of transport.

Transport services can also be improved with an increased focus on walking and cycling facilities to promote more active forms of transport, a greater focus on spatial planning of local areas to ensure that residential areas, services and transport links are geographically close and investment in rural and urban public transport to reduce the reliance on cars. Promoting active travel has a number of benefits including improved health, increased 
interactions with other travellers, reduced expenditure on fuel and vehicle maintenance, reduced greenhouse gas emissions and lower costs to maintain road infrastructure (Lavin et al, 2011).

In conclusion, there is no question that mobility and transport are important for health and wellbeing. There is an increasing need for improved transport networks and facilities that meet the specific needs of older adults, especially in rural areas. Retaining public transport links and/or identifying alternative means of providing transport is required, and this is especially pertinent given the challenges facing policymakers about the provision of suitable transport services. 


\section{References}

1. Ahern A, Hine J. Transport needs of older people in rural Ireland. In: Ghosh, B. (ed.). Proceedings of the inaugural conference of the Irish Transport Research Network (ITRN) University College Dublin, Dublin, 31 August-1 September 2010. Available at: http://hdl.handle.net/10197/2880.

2. Chihuri S, Mielenz TJ, DiMaggio CJ, Betz ME, DiGuiseppi C, Jones VC, Li G. Driving Cessation and Health Outcomes in Older Adults. Journal of American Geriatric Society. 2016; 64(2):332-41.

3. Davey JA. Older people and transport: coping without a car. Ageing \& Society. 2007; 27: 49-65.

4. Donoghue O, O'Connell M, Kenny RA. Walking to Wellbeing: Physical Activity, Social Participation and Psychological Health in Irish adults aged 50 years and Older. The Irish Longitudinal Study on Ageing (TILDA), Dublin, January 2016.

5. Gilhooly M, Hamilton K, O'Neill M, Gow J, Webster N, Pike F. (2003) Transport and Ageing: Extending Quality of Life via Public and Private Transport. ESRC Research Findings from the Growing Older Programme 16, Economic and Social Research Council, Swindon, Wiltshire.

6. Green J, Jones A, Roberts H. More than A to B: the role of free bus travel for the mobility and wellbeing of older citizens in London. Ageing \& Society 2004; 34: 472-494.

7. Hawkley LC, Cacioppo JT. Loneliness matters: a theoretical and empirical review of consequences and mechanisms. Annals of Behavioural Medicine. 2010; 40(2):218-27.

8. Holley-Moore $\mathrm{G}$, Creighton $\mathrm{H}$. The future of transport in an ageing society. International Longevity Centre - UK, 2015. Available at: http://www.ilcuk.org.uk/index.php/ publications/publication_details/the_future_of_transport_in_an_ageing_society 
9. House JS, Robbins C, Metzner HL. The association of social relationships and activities with mortality: prospective evidence from the Tecumseh Community Health Study. American Journal of Epidemiology. 1982; 116(1):123-40.

10. House J, Landis K, Umberson D. Social relationships and health. Science. 1988;241(4865):540-5.

11. Hyde M, Wiggins RD, Higgs $P$, Blane DB. A measure of quality of life in early old age: the theory, development and properties of a needs satisfaction model (CASP-19). Aging and Mental Health. 2003; 7(3):186-94.

12. Lavin T, Metcalfe O, Higgins C. Active travel - healthy lives. The Institute of Public Health in Ireland, 2011. Available at: http://www.publichealth.ie/activetravel.

13. Lum TY, Lightfoot E. The Effects of Volunteering on the Physical and Mental Health of Older People. Research on Aging. 2005; 27(1):31-55.

14. Lynott J, Figueiredo C. How the Travel Patterns of Older Adults Are Changing: Highlights from the 2009 National Household Travel Survey. AARP Public Policy Institute. 2009. Available at: http://assets.aarp.org/rgcenter/ppi/liv-com/fs218transportation.pdf

15. Pobal. Rural Transport Programme Performance and Impact Report 2013: Rural transport Connecting Rural Ireland. 2014, Available at: https://www.pobal.ie/ Publications/Documents/RTP\%20Performance\%20and\%20Impact\%20Report\%20 2013.pdf

16. Radloff LS. The CES-D Scale: A Self-Report Depression Scale for Research in the General Population. Applied Psychological Measurement. 1977; 1(3):385-401.

17. Russell DW. UCLA Loneliness Scale (Version 3): reliability, validity, and factor structure. Journal of Personality Assessment. 1996; 66(1):20-40.

18. Siegrist J, Wahrendorf M. Participation in socially productive activities and quality of life in early old age: findings from SHARE. Journal of European Social Policy. 2009;19(4):317-26. 
19. Victor CR, Scambler SJ, Bowling A, Bond J. The prevalence of, and risk factors for, Ioneliness in later life: a survey of older people in Great Britain. Ageing \& Society. 2005; 25(6):357-75. 